\title{
Cytological study on hypo-pentaploid Triticale with four B chromosomes of rye
}

\author{
BY Hidetoshi KISHIKAWA and Akitaka SUZUKI \\ Laboratory of Plant Breeding, Faculty of Agriculture, \\ Saga University, Honjo, Saga 840
}

(Received July 8, 1981)

\begin{abstract}
Hypo-pentaploid Triticale with four B chromosomes $(2 n=33+4 \mathrm{~B}$ 's $)$ derived from (Triticum durum $\times$ Secale cereale with $2 \mathrm{~B}$ 's) $\times$ T. durum was cytologically studied, particularly on the normal chromosome component and on the behaviour of $\mathrm{B}$ chromosomes.

As a result of Giemsa staining for meiotic metaphase in pollen mother cells it was made clear that the normal chromosome component in the present Triticale consisted of 27 chromosomes of T. durum and 6 ones of S. cereale. The present Triticale showed a highly disturbed meiotic pattern. At MI the modal configuration of chromosomes was found in $12_{\text {II }}+9_{1}+2 B_{\text {II. }}$. At AI the unequal distribution in number and the many lagging chromosomes were observed, but the micronuclei at tetrad were a small number.

The number of $\mathrm{B}$ chromosomes in the present Triticale, $\mathrm{BF}_{1}$ plant, was twice as many as $F_{1}$ parent. This indicates that in Triticale the nondisjunction of B chromosomes also takes place as well as in the original rye plant. The degree of multivalent formation between the $\mathbf{B}$ chromosomes was much lower in the present Triticale than in the original rye plants with 4B's. This indicates that the meiotic pairing of $\mathrm{B}$ chromosomes is disturbed by the change of genetic environment.
\end{abstract}

\section{INTRODUCTION}

So far the cytological behaviour and genetical effects of B chromosomes in rye heve been extensively studied in the diploid level by many investigators (Kishikawa 1965; Müntzing 1974), and also in the autopolyploid environment by Sarvella (1959), Müntzing (1963) and Kishikawa (1966). When considering a new reaction of $B$ chromosomes, it seems desirable to rescrutinize the nature and function of $\mathrm{B}$ chromosomes in rye by transferring these chromosomes to an entirely new genetic environment. In this way, as described by Lindström (1965) in a posthumous paper formulated by Müntzing, it was possible to transfer B chromosomes of an allogamous species, Secale cereale L., to an autogamous species, Triticum aestivum $\mathrm{L}$. The B chromosomes in allohexaploid wheat, the so-called Lindström strain, have been studied by Müntzing et al. (1969) and Müntzing $(1970,1973)$.

It would be interesting to transfer the $B$ chromosomes in rye to an allotetraploid species of wheat, and to be compared with the data obtained on the 
B chromosomes at the autopolyploid and allohexaploid level mentioned above. Therefore, crosses between allotetraploid wheat and rye with $B$ chromosomes, and Lindström strain, have been carried out. In a series of studies, the present paper deals with the cytological studies on the hypo-pentaploid Triticale with four B chromosomes, which found in the backcrossed hybrids between tetraploid wheat and rye with B chromosomes, particularly on the normal chromosome component and the cytological behaviour of B chromosomes.

\section{MATERIALS AND METHODS}

The tetraploid wheat parent used in the crossing was Triticum durum Desf. var. reichenbachii Körn. $(2 \mathrm{n}=28, \mathrm{AABB})$ and the rye parent a Japanese strain (JNK), Secale cereale L. (RR), with two standard B chromosomes $(2 \mathrm{n}=14+2$ $B$ 's). The resulting $F_{1}$ plants $(A B R)$ with two standard $B$ chromosomes $(2 n=$ $21+2 \mathrm{~B}$ 's) were backcrossed with wheat parent mentioned above. This $\mathrm{BF}_{1}$ plant was used in the present investigation.

For observations of somatic chromosomes the excised root tips were pretreated for about twenty hours in ice-water $\left(\right.$ ca. $\left.0^{\circ} \mathrm{C}\right)$ and then fixed in alcoholacetic acid (3:1). For studies of meiosis the young spikes were fixed in alcoholchloroform-acetic acid $(6: 3: 2)$. The cytological preparation for both root tip cells and pollen mother cells were made with a staining and squash method employing alcoholic hydrochloric acid-carmine described by Snow (1963). Identification of rye chromosomes in the $\mathrm{BF}_{1}$ plant was made with Giemsa staining technique in meiotic chromosomes described by Singh and Lelley (1975).

\section{RESULTS AND DISCUSSION}

At mitotic and meiotic metaphase $B$ chromosome can easily be distinguished by its smaller size and subterminal centromere position from normal chromosomes. All of B chromosomes occurred in the present materials were a standard type. The somatic chromosomes of $\mathrm{F}_{1}$ and $\mathrm{BF}_{1}$ plants, as shown in Figs. 1 and 2 , were $2 n=21+2$ B's and $2 n=33+4$ B's, respectively. The number of normal chromosomes in $\mathrm{BF}_{1}$ plant was less by 2 than eu-pentaploid number, 35. This indicates that the present $\mathrm{BF}_{1}$ plant is a hypo-pentaploid Triticale having four B chromosomes.

In order to elucidate the normal chromosome component in the present Triticale, Giemsa staining technique was employed for meiotic metaphase chromosomes. Consequently, as shown in Fig. 3, 6 of univalents showed distinct band at one end or both ends (cf. Lelley 1975). They are clearly the chromosomes of rye. This indicates that 33 of chromosomes in the present Triticale consist of 6 chromosomes of rye and 27 ones of wheat. Because the chromosome complement $(n=14)$ in the gametes of tetraploid wheat used as the recurrent parent is entirely normal, the numerically aberrant chromo- 

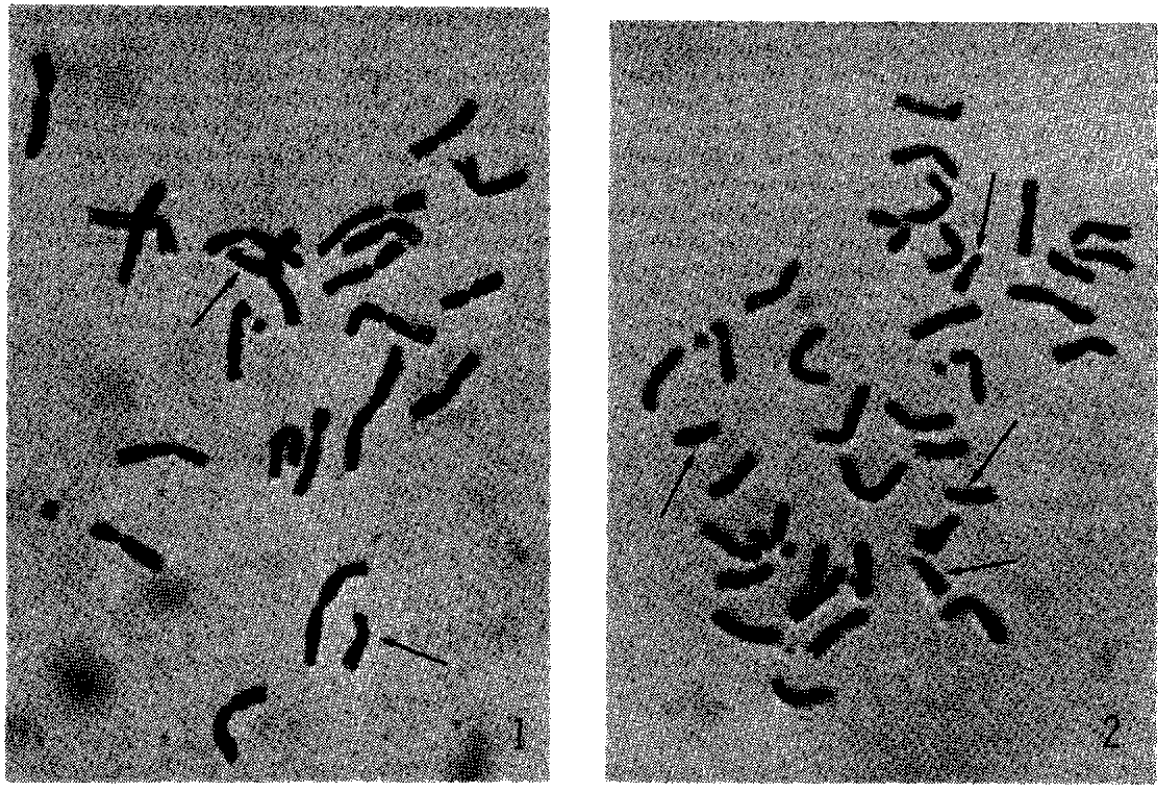

Figs. 1 and 2. Somatic chromosomes in root tip cells of wheat-rye hybrids. (Arrows indicate $\mathrm{B}$ chromosomes.)

Fig. 1. F 1 plant: $2 n=21+2$ B's. Fig. 2. BF 1 plant: $2 n=33+4$ B's.

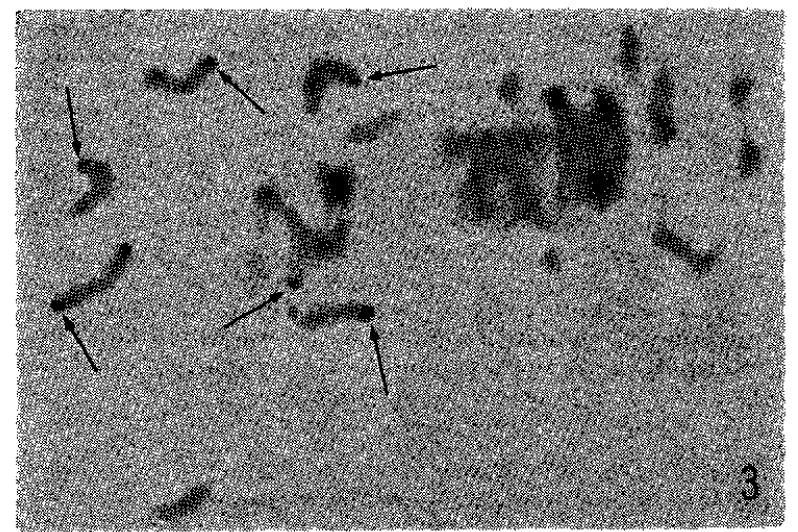

Fig. 3. 6 univalents of rye (arrows) recognizable by terminal Giemsa bands at meiotic metaphase $\mathrm{I}$ in $\mathrm{BF}_{1}$ plant.

somes $(n=19)$ resulted from the irregular gametogenesis in $F_{1}$ plant (Kishikawa and Nagai, unpublished; cf. Nakajima 1951, 1952) may be contributed to the occurrence of the present aneuploid.

On the other hand, the present $\mathrm{BF}_{1}$ plant had twice as many $\mathrm{B}$ chromosomes as $F_{1}$ parent. This is due to the non-disjunction of $B$ chromosomes occurred in 
Table 1. Chromosome pairing at metaphase I in hypopentaploid Triticale with four $B$ chromosomes

\begin{tabular}{|c|c|c|}
\hline \multicolumn{2}{|c|}{ Configurations } & \multirow{2}{*}{$\begin{array}{l}\text { No. of } \\
\text { cells } \\
\text { observed }\end{array}$} \\
\hline Normal chromosomes & B chromosomes & \\
\hline $13_{\mathrm{II}}+7_{\mathrm{I}}$ & $1_{\mathrm{IV}}$ & 1 \\
\hline$" \prime \prime$ & $\mathbf{2}_{\mathrm{II}}$ & 1 \\
\hline $12_{\mathrm{II}}+9_{\mathrm{I}}$ & $1_{\mathbf{I V}}$ & 20 \\
\hline$" \prime \prime$ & $1_{\mathrm{III}}+1_{\mathrm{I}}$ & 1 \\
\hline$"$ & $2_{\text {II }}$ & 50 \\
\hline$"$ & $1_{I I}+2_{I}$ & 10 \\
\hline$"$ & $4_{I}$ & 1 \\
\hline $11_{1 I}+11_{I}$ & $1_{\mathrm{IV}}$ & 4 \\
\hline " " & $\mathbf{2}_{\mathrm{II}}$ & 8 \\
\hline$" \quad "$ & $1_{I I}+2_{I}$ & 4 \\
\hline $10_{\mathrm{II}}+13_{\mathrm{I}}$ & 2 & 2 \\
\hline$" \prime \prime$ & $\mathbf{4}_{\mathrm{I}}$ & 1 \\
\hline $9_{\mathrm{rI}}+15_{\mathrm{I}}$ & $2_{I I}$ & 2 \\
\hline \multicolumn{2}{|c|}{ Total } & 105 \\
\hline
\end{tabular}
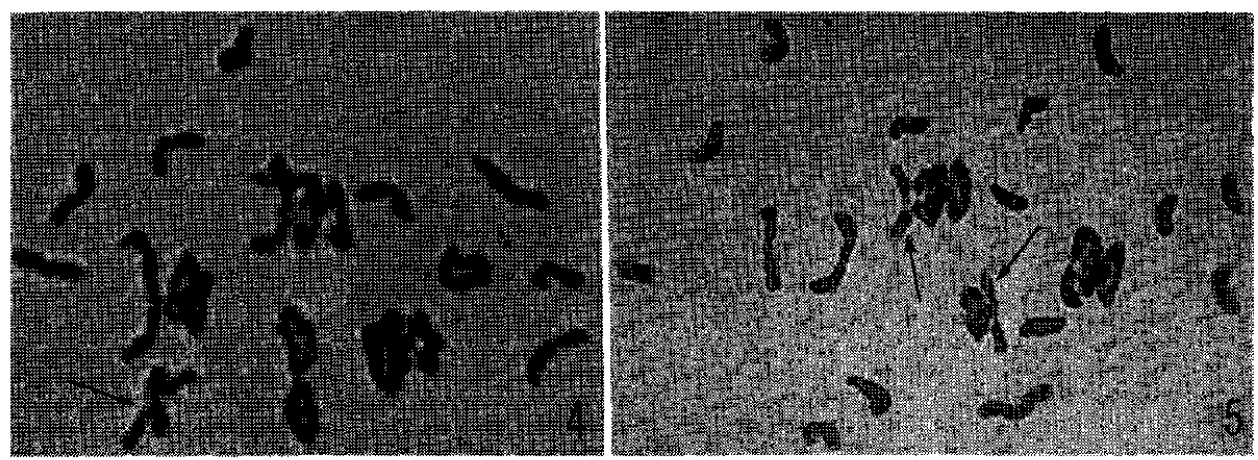

Figs. 4 and 5. Chromosome configurations at meiotic metaphase I in hypo-pentaploid Triticale with four B chromosomes. (Arrows indicate B chromosomes.)

Fig. 4. $12_{\mathrm{II}}+9_{\mathrm{I}}+1 \mathrm{~B}_{\mathrm{IV}}$. Fig. 5. $10_{\mathrm{II}}+13_{\mathrm{I}}+2 \mathrm{~B}_{\mathrm{II}}$.

the ovules of $F_{1}$ parent. This indicates that in Triticale the non-disjunction of $B$ chromosomes also takes place in the first pollen mitosis and the corresponding stage in the ovules, just as in the original rye plant (Müntzing 1946; Kishikawa 1965) and Lindström strain (Müntzing 1970).

The present Triticale showed a highly disturbed meiotic pattern.

Data on the chromosome pairing at meiotic metaphase I are summarized in Table 1, and the configurations are shown in Figs. 4 and 5. The modal con- 
Table 2. Frequency of $B$ chromosome pairing at $M I$ in the different plants with four $B$ chromosomes

\begin{tabular}{cccc}
\hline \multirow{2}{*}{ Cofigurations } & \multicolumn{3}{c}{ Plants with 4 B's } \\
\cline { 2 - 4 } & $5 x-2$ Triticale & $2 x$ Rye* $^{*}$ & $3 x$ Rye* \\
\hline $1_{\text {IV }}$ & $23.8 \%$ & $74.0 \%$ & $54.5 \%$ \\
$1_{\text {III }}+1_{\text {I }}$ & 1.0 & 3.0 & 2.5 \\
$2_{\text {II }}$ & 60.0 & 21.4 & 40.0 \\
$1_{\text {II }}+2_{\text {I }}$ & 13.3 & 1.6 & 3.0 \\
$4_{\text {I }}$ & 1.9 & 0.0 & 0.0 \\
\hline No. of cells & 105 & 800 & 200 \\
\hline
\end{tabular}

Note: * These data were quoted from the data of Kishikawa (1966).

Table 3. Frequency of $B$ bivalents at $M I$ in $F_{1}$ plants ( $T$. durum $\times$ S. cereale with $2 B$ 's) and the original rye plants with two $B$ chromosomes

\begin{tabular}{ccc}
\hline Configurations & $\mathrm{F}_{1}$ & Rye \\
\hline $1_{\mathrm{II}}$ & $28.5 \%$ & $92.4 \%$ \\
$2_{\mathrm{I}}$ & 71.5 & 7.6 \\
\hline No. of cells & 260 & 630 \\
\hline
\end{tabular}

figuration of chromosomes was found in $12_{\mathrm{II}}+9_{\mathrm{I}}+2 \mathrm{~B}_{\mathrm{I}}$. As for the pairing of normal chromosomes, the number of bivalent per cell ranged from 9 to 13 with an average of 11.8 , and the univalent from 7 to 15 with an average of 9.4. All bivalents are considered to be based on the allosyndesis among chromosomes of wheat parent, because as a result of Giemsa staining the chromosomes of rye behave always as the univalents (Fig. 3). The maximum class of configuration, $13_{\mathrm{II}}+7_{\mathrm{I}}$, is composed of 13 bivalents and 1 univalent of wheat chromosomes, and 6 univalents of rye. In other words, the present aneuploidy is due to the loss of one chromosome of wheat and rye, respectively.

As for the pairing of $B$ chromosomes, the configurations and their frequencies were summarized in Table 2 by extracting the data from Table 1, in comparison with the data from the original rye plants (JNK strain), both diploid and triploid with four B chromosomes, reported previously (see Kishikawa 1966, p. 430). In the present Triticale B chromosomes paired fairly well with one another, and the same configurations as in the original rye plants were observed. The quadrivalent also was characterized by radial association. There is, however, a great difference between the degree of pairing of the B chromosomes in the original rye plants and in the present Triticale. That is, the frequency of quadrivalent and trivalent was much lower in the present 
Table 4. Chromosome separation at anaphase I in hypo-pentaploid Triticale with four B chromosomes

\begin{tabular}{|c|c|}
\hline Distributions & $\begin{array}{l}\text { No .of } \\
\text { cells } \\
\text { observed }\end{array}$ \\
\hline 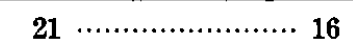 & 1 \\
\hline $20 \ldots \ldots \ldots \ldots \ldots \ldots \ldots \ldots \ldots \ldots \ldots \ldots$ & 2 \\
\hline 19 & 1 \\
\hline \multicolumn{2}{|l|}{ Laggards: } \\
\hline $20 \ldots \ldots \cdots \cdots$ & 1 \\
\hline $17 \ldots \ldots \ldots, \quad 4 \quad \cdots \cdots \cdots \cdots$ & 1 \\
\hline $16 \quad \cdots \cdots \cdots \cdots$ & 1 \\
\hline $17 \quad \ldots \ldots \ldots, \quad 6 \quad \cdots \cdots \cdots, 14$ & 2 \\
\hline $16 \quad \ldots \ldots \cdots, \quad 6 \quad \ldots \cdots \cdots \cdots$ & 2 \\
\hline 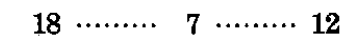 & 1 \\
\hline $16 \quad \ldots \ldots \ldots . \quad 7 \quad \ldots \ldots \ldots . .14$ & 6 \\
\hline $\begin{array}{lllllll}15 & \cdots \cdots \cdots & 7 & \cdots \cdots \cdots & 15 \\
15 & \cdots \cdots \cdots & & 8 & \cdots \cdots \cdots & 14\end{array}$ & $\begin{array}{r}2 \\
17\end{array}$ \\
\hline $15 \quad \ldots \ldots \ldots . \quad 9 \quad \ldots \ldots \ldots 13$ & 8 \\
\hline $14 \ldots \ldots \ldots . \quad 9 \quad \ldots \ldots \ldots 14$ & 27 \\
\hline $14 \ldots \ldots \ldots \ldots \ldots \ldots$ & 12 \\
\hline $14 \ldots \ldots \ldots 11$ & 2 \\
\hline $13 \ldots \ldots \ldots, 11 \ldots \ldots \ldots 13$ & 8 \\
\hline $15 \quad \cdots \cdots \cdots, 12 \cdots \cdots \cdots \cdots$ & 1 \\
\hline $13 \ldots \ldots \cdots 12 \quad \ldots \cdots \cdots, 12$ & 4 \\
\hline $11 \quad \cdots \cdots \cdots, 15 \cdots \cdots \cdots \cdots$ & 1 \\
\hline Total & 100 \\
\hline
\end{tabular}
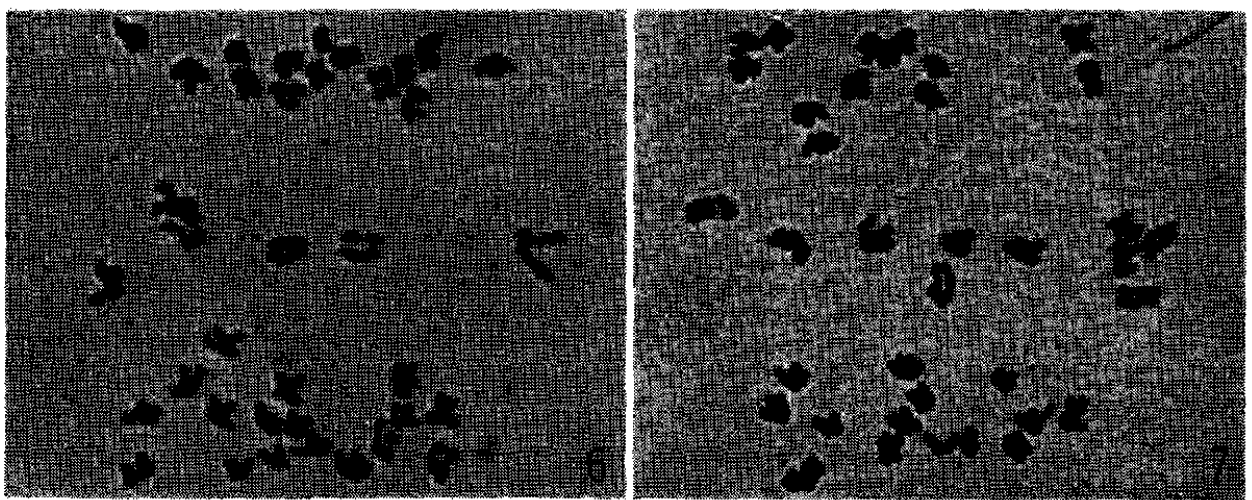

Figs. 6 and 7. Chromosome distributions with laggards at meiotic anaphase I in hypopentaploid Triticale with four B chromosomes.

Fig. 6. 17-6-14. Fig. 7. 14-10-13. 
Triticale than in the original diploid and even the triploid plant, while the one of bivalent and univalent higher. This indicates that the multivalent formation of $\mathrm{B}$ chromosomes in the present Triticale is far inferior to that in the original rye plants. In this connection, Kishikawa and Nagai (unpublished) have found that in $F_{1}$ plant with two $B$ chromosomes, a parent of the present Triticale, the frequency of $\mathrm{B}$ bivalents was strikingly lower than in the original rye plants with two $B$ chromosomes, as is evident from Table 3 . One possible cause of the low frequency of meiotic pairing between the $\mathrm{B}$ chromosomes may be a disturbance of the pairing of $B$ chromosomes with the irregular division at meiosis in polyhaploid $\left(\mathrm{F}_{1}\right)$ and aneuploid $\left(\mathrm{BF}_{1}\right)$. Müntzing et al. (1969) also have reported that the degree of meiotic pairing of the B chromosomes was much lower in Lindström strain in which the $B$ chromosomes of rye occur together with the 42 wheat chromosomes than in the original rye variety, "Transbaikal". This fact is essentially identical to the present result, although both materials differ much in the genotypical constitution from each other. The most plausible cause of the reduced meiotic pairing of the $B$ chromosomes, as Müntzing pointed out, seems to be a disturbing effect of the wheat chromosomes or its cytoplasm. And also, it has been reported that the pairing of B chromosomes in rye was much poorer in the autotetraploid (Sarvella 1959) and in the autotriploid (Kishikawa 1966) than in the original diploid.

Judging from the facts described above, it seems most reasonable to conclude that the meiotic pairing of $\mathrm{B}$ chromosomes is disturbed by the change of genetic environment, such as from diploid to autopolyploid in rye and from rye to wheat.

The chromosome segregation at meiotic anaphase I in the present Triticale was strikingly irregular. The data are summarized in Table 4, and the distribution of chromosomes is shown in Figs. 6 and 7. In all of AI cells the unequal distribution in number and many lagging chromosomes were observed. The number of lagging chromosomes ranged from 1 to 15 with an average of 8.5. In this stage it was difficult to distinguish $B$ chromosomes from normal ones. Normal chromosomes, however, may be responsible for most of lagging chromosomes as a result of the predominant occurrence of univalent at metaphase I. The lagging chromosomes may lead to the occurrence of micronuclei

Table 5. Number of micronuclei at tetrad stage in hypo-pentaploid Triticale with four B chromosomes

\begin{tabular}{cccccccccc}
\hline & \multicolumn{1}{c}{ Number of micronuclei per tetrad } & \multirow{2}{*}{ Total } \\
\cline { 2 - 11 } & 0 & 1 & 2 & 3 & 4 & 5 & 6 & 7 & \\
\hline $\begin{array}{l}\text { No. of tetrads } \\
\%\end{array}$ & 36 & 48 & 114 & 30 & 40 & 23 & 5 & 4 & 300 \\
& 12.0 & 16.0 & 38.0 & 10.0 & 13.3 & 7.7 & 1.7 & 1.3 & 100 \\
\hline
\end{tabular}


at tetrad stage. Actually, in most of cells at this stage the micronuclei were observed. The number of micronuclei is given in Table 5 as the sum of micronuclei included in four daughter cells. Their number ranged from 1 to 7 with an average of 2.3. In spite of a large number of occurrence of the lagging chromosomes at anaphase $I$, the number of micronuclei at tetrad stage was much fewer than expected. This indicates that most of lagging chromosomes may reach finally the daughter nuclei at telophase I and II.

\section{REFERENCES}

KISHIKAWA, H. (1965) Cytogenetic studies of B chromosomes in rye, Secale cereale L. in Japan. Agr. Bull. Saga Univ. 21, 1-81 (in Japanese with English summary).

KishiKaWA, H. (1966) Cytological studies on triploid rye with four accessory chromosomes. Jpn. J. Genet. 41, 427-437.

LELLEY, T. (1975) Identification of univalents and rod bivalents in Triticale with Giemsa. $Z$. Pflanzenzüchtg. 75, 252-256.

LINDSTRÖM, J. (1965) Transfer to wheat of accessory chromosomes from rye. Hereditas 54, 149155.

MUntzing, A. (1946) Cytological studies of extra fragment chromosomes in rye. III. The mechanism of non-disjunction at the pollen mitosis. Hereditas 32, 97-119.

MUNNTZING, A. (1963) Effects of accessory chromosomes in diploid and tetraploid rye. Hereditas 49, 371-426.

MÜNTZING, A. (1970) Chromosomal variation in the Lindström strain of wheat carrying accessory chromosomes of rye. Hereditas 66, 279-286.

MUNTZING, A. (1973) Effects of accessory chromosomes of rye in the gene environment of hexaploid wheat. Hereditas 74, 41-56.

Müntzing, A. (1974) Accessory chromosomes. Ann: Rev. Genetics 8, 243-266.

MÚnTZing, A., JAWORSKA, H. and CARLBOM, C. (1969) Studies of meiosis in the Lindström strain of wheat carrying accessory chromosomes of rye. Hereditas 61, 179-207.

NaKajima, G. (1951) Cytogenetical studies of $F_{1}$ plants raised between Triticum dicoccum $(n=$ 14) and Secale cereale $(\mathrm{n}=7)$. La Kromosomo 11, 410-415 (in Japanese with English résume).

NAKAJIMA, G. (1952) Cytological studies on intergeneric $F_{1}$ hybrid between Triticum and Secale, with special reference to the number of bivalents in meiosis of PMC's. Cytologia 17, 144155.

SARVELla, P. (1959) The behaviour of accessory chromosomes in tetraploid rye. Hereditas 45, 505-563.

SingH, R. J. and LeLLeY, T. (1975) Giemsa banding in meiotic chromosomes of rye, Secale cereale L. Z. Pflanzenzüchtg. 75, 85-89.

SNow, R. (1963) Alcoholic hydrochloric acid-carmine as a stain for chromosomes in squash preparations. Stain Technology 38, 9-13. 